\title{
Contemplation of Suicide -- An Interdisciplinary Study Yi Lan
}

\author{
Pomfret School, Pomfret, Connecticut 06258, United States of America. \\ Email: ylan.22@pomfret.org
}

\begin{abstract}
This essay is a failure. I failed to answer whether we should suicide or not. I studied three distinct lenses, including the analytical, sociological and existential lens, each with its own set of axioms and methodology. I then gave an analysis of the approaches and provided some suggestions on what you should do.
\end{abstract}

Keywords: Suicide, Interdisciplinary, Comparative, Existentialism, Ethics.

\section{INTRODUCTION}

In the following text, I will present the general approach to problems from three lenses and then sample a few examples from each lens for further analysis. By reviewing the literature published on a topic, we can enrich ourselves with the wisdom of the old and find the echoes of our own thoughts in the past. The three lenses are three very distinct ways to view the world, each influential in their respective spheres. Because the axioms of these ways of thinking are different, they are not merely perspectives, which differ in what part of the thing it is seeing, but more like lenses, which are different in their complete vision of the thing. These lenses differ in the questions they ask, method of assessment and the goal of their assessment. Through carefully contrasting the differences between the lenses, the overall shape of a topic emerges. Studying from one perspective can be limiting, and once one's idea on a subject is formulated, one's system of interpretation can be difficult to shift, and therefore stuck. Studying multiple lenses makes each lens' limitation starkly clear and explores the broad horizon of possibilities to save ourselves from drowning in lengthy texts and blind faith. Comparing possibilities is especially important in suicide, for one of the greatest dangers, or worries, of suicide is the irreversible nature of it. On such occasions, the more limited one's knowledge is, the more likely one will act upon prejudice.

The three lenses are chosen because they are each the exemplar of a rigorous approach to suicide and indeed the world that is worth a serious study. The analytical lens is the epitome of empirical rational thinking, or at least the attempt of it. It is complete in its reasoning and easy to communicate through precise language. The sociological lens is the epitome of environmental thinking, reminding us of the obvious and hidden factors that influence our decisions. The existential lens is the epitome of phenomenological thinking, which starts from our intuition and enriches our selfhood. I will go on to explore them in more depth in the following text. A lens that was abridged in the process of writing this text is the religious lens, which includes a group of arguments that I consider religious. These arguments appeal to an ultimate authority, and any challenge to their argument is considered blasphemous. Not all arguments that are related to religion are unworthy of careful study; many people, such as Aquinas, Spinoza, Berkeley, Kierkegaard, and Durkheim, have interesting religiouslyrelated ideas worth investigating. The religious arguments I left out from this paper are the lazy arguments. These people appeal to dogma, like how sociologists appeal to culture.

There exist sociologists whose only answer to any question is "culture". Why did Europe conquer America? Culture! The Europeans, with their superior culture, conquered the culturally barbaric American natives. Why did National Socialism become prominent in Germany during the interwar years? Culture! An appeal to authority runs in the blood of every German whose culture breeds a dictator. Why does Germany have the highest GDP among nations in the European Union? Culture! German culture encourages good work ethics, industrial mindset and craftsmanship, unlike their neighbour France whose culture encourages romance and creativity. The answer "culture" is a lazy one and should not be the answer to dwell on. The answer bases itself upon mostly inaccurate stereotypes, and even if the characteristics described in the cultures are accurate, there is always a deeper layer of knowledge, an underlying reason that caused the culture to be what it is. Perhaps the behaviour observed originates 
from the geographical features a group inhabits, climate experienced by a group or the history of a group. Thus, the appeal to culture is like the appeal to god, for they both skim the surface and lack depth. On the other hand, the lenses I picked are thoughtful in their origin, rigorous in their method and thorough in their analysis.

Before discussing the particular lenses, I want to clarify the concept of a lens. The idea of lenses describes how people see the world. I used the word see instead of observing to include the possibilities proposed by people like Binswanger [1], who suggests that we see meaning first rather than objects. The systems of ideas I am bringing up differ more than just seeing an object from different angles; instead, the difference is more profound, for these systems of ideas are playing completely different games in entirely different systems. The systems are just like video games. They all have their own underlying mechanics, perhaps codes in different game engines. They have different settings; some set in the wild west, others set in the grim future. They have different playing styles; some are about shooting, and others about roleplaying. They have different victory conditions; each game has its own problems that you have to conquer using the toolkit provided by the developers. In summary, a lens is not only an idea, but a system of ideas that influences our way to see, make sense and act in the world.

For the reasons above, I decided to bring up the analytical lens, the sociological lens, and the existential lens to explore three significant ways of thinking on suicide, and I will analyse them after I introduce them.

\section{ANALYTICAL LENS}

\subsection{Pin-point the question}

The question at hand is whether suicide is reasonably sensible. It can be convenient to think of them as standards, one of morality, the other reason. We then put the act of suicide to the test using these standards and then see their outcome. Some views suggest that suicide should or should not be allowed because of a certain right, a specific responsibility or a kind of sanctity.[2,3] However, these arguments will not be discussed, as previously explained in the introduction. Instead, I will assume people can suicide and then assess the utilitarian view of suicide, a method that can help you to determine whether you should suicide, which to me is an exemplar of a particular lens to view suicide.

\subsection{The total area of life}

"If the goods that life holds are, in general, reasons against killing, those reasons lose all their force when it is clear that those killed will not have such goods, or that the goods they have will be outweighed by bad things that will happen to them." [4]
The utilitarian view can be summarised as the following: If the bad things of life outweigh the good things of life, then you should suicide. However, the word "outweigh" can be a difficult one to interpret. After all, to outweigh something, you must have a scale to weigh the things. The scale I will discuss in the following text is the following, quality and quantity. The imagery of an area graph can be helpful in helping us to determine if we should kill ourselves. Let the quantity of life be the x-axis and the quality of life be the $y$-axis. Do remember to leave out space below the $\mathrm{x}$-axis, for we are allowing the possibility of terrible things that can fall below 0 . Plot points according to quality and quantity, and then link all the points together. Calculate the total area of the graph above the line and compare it with the total area below the line. If your answer is negative, bad things outweigh the good things; you should suicide.

From the rules set above, perhaps the following scenario is the paradigm case of suicide:

Paradigm Scenario: Your life is filled with good, above 0 experiences until, at one point, your life rapidly declines until you die of natural causes. If the total area from the beginning of your life to its natural end is negative, then to avoid the pain, suicide is a reasonable option.

\subsubsection{X-axis Quantity of life}

Quantity of life is how long your life is, the time of it. The concept of time becomes tricky when the sequence of events is considered.

\section{Consider two scenarios:}

First Scenario: All the bad things happen during the beginning of your life, and then your life starts to get better.

Second Scenario: All the good things happen during the beginning of your life, and then your life starts to get worse.

Suppose if we graph these two lives and the area is exactly the same, do you prefer one life to another? If your answer is yes, then perhaps we need some form of age index that can be applied to each event because otherwise, the two lives would be indistinguishable.

Imagine the following case:

Third Scenario: Your life is good until at some point it rapidly declines, dipping below 0 and never comes up again. Still, the total area of your life will be positive. Perhaps you had a fulfilling life for 80 years, but in your last four years of life, a terrible disease got you, and you suffer from it until you die because of it.

The total area of your life is still positive, which means the bad things never outweigh the good things, but if you choose suicide, say euthanasia, your total area of 
life would be bigger than if you didn't. Should you still hold on to your life on such an occasion even if you know that what is left is only absolute suffering? From the total area point of view, the total positive area you accumulated for most of your life is not all "spent" by the pain from the last years of your life, so suicide should be avoided. But some might say this is just like the paradigm case of suicide because what you really want to do is to avoid pain, so suicide in the form of voluntary euthanasia makes a lot of sense.[4] Compare the third scenario with the scenario below.

Taking the first scenario to the extreme:

Fourth Scenario: You have multiple terminal illnesses that torment your life or a terrible family that abuses you. The first ten years of life is absolute torture, below 0 experience, but somehow sometime in the eleventh year, a miracle happened, new medicine got invented perhaps, and all your disease got cured. Afterwards, you lived happily ever after.

The fourth scenario is essentially the third scenario but reversed. Suppose the areas of these two scenarios are the same, both positive numbers, is the answer to whether you should suicide or not different for the two scenarios? If your answer is yes, then the sequence of events matters in addition to the total area of life.

\subsubsection{Y-axis Quality of life}

Quality is a far more nebulous term than quantity. One of the questions that quickly arises is on what standard should the quality of one's life be judged. There are multiple views on this subject, but before we go into them, I must remind you of the speciality of suicide. Because when someone is killing herself, she is ending her life, not anyone else's. So we should consider utility here slightly different from how we consider utility when debating about policies, which involves more than one entity. (explain)

There is, of course, the hedonistic view of utility that claims utility is pleasure, which has to be calculated against pain [5], and other views that say pleasure and pain are not all, perhaps beauty [6], fairness, freedom or other qualities should also be considered. Whatever one's theory of utility is, one has to confront the question, to whom should have the power to judge what utility is and how much utility there is. Some might suggest the state should determine utility or that utility should be studied as a science so we can be very precise about it. However, due to the personal nature of suicide, the view of preference utilitarians is particularly worth mentioning. Preference Utilitarianism states that what utility is is what fulfils the most amount of personal interest.[7] Since personal interest is at the forefront of such a stand, it might not be as useful in social circumstances, such as policy debates that affect billions of people; we surely don't want one man's preference to be the preference of all. Nevertheless, in the case of suicide, the person herself is at the centre, which means that using Preference Utilitarianism as our guidance is not inappropriate at all.

There also exists an argument that urges the consideration of the impact of suicide.[8] Suicide can leave family members in pain, relative to how strong the familial relationship is, cause a violation of duty, say an army commander suicide and leave ten-thousand men in disarray. Arguments as such works to some extent. We certainly want to consider the feelings of others when making decisions, but we don't want other people's feelings to dictate our decision, especially if the decision is an important one. If what we do should adhere to what others feel or want to feel, then to some extent, we are their vassals, dominated by others' will, and for many of us, we clearly can choose not to be like that. We should be the ones weighing all the consequences of an action and then make a decision, and even if we consider the feelings of others, the consideration should still originate from ourselves. Being "selfish" is no "sin" when contemplating suicide because whatever others have on the table of consideration is no match for your life.

Thus, the view that the quality of life should be determined by the one living it, and the quality is what one prefers is a sensible one to consider amongst the utilitarian theories on suicide.

Another thing worth considering when discussing the quality of life is how high is the apex on the graph of life. You can easily live a life of fulfilment if you set modest goals and achieve them, but the peak of the graph on the $\mathrm{y}$-axis matters on some occasions.

\section{Consider the following scenarios:}

Fifth Scenario: Your life is very short but full of escapades that only a few people on earth will ever experience. So the graph would go very tall but very thin.

Sixth Scenario: Your life is very long but very dull. You lived perhaps for a hundred and fifty years, but your life, perhaps solely devoted to the continuation of your life, has nothing significant to it. So the graph would go very short but very wide.

Suppose the total area of the Fifth Scenario and the Sixth Scenario is the same; do you prefer one life to another? Do you prefer to be like the romantic poets, who go on adventures throughout the world but die when you are thirty or be like a recluse, who lives a bland but long life? If you prefer one over the other, perhaps an adventurous but short life over a long but boring one, then not only does the quality of life matter, the peak of quality matters too. What if the total area of the Fifth Scenario is smaller than the Sixth Scenario? If you prefer one over the other, then either the peak or the longevity of life is what absolutely matters. One that wishes to live long certainly doesn't want to suicide, but one who values the peak more may reasonably consider the life after the peak 
not worth living. People like Hölderlin had written poems like "To the Parcae", which says that "I shall be satisfied though my lyre will not accompany me down there. Once I lived like the gods, and more is not needed."

\subsection{Conclusion}

The scenarios above are powerful challenges to the view that all that matters when determining suicide is whether the good things outweigh the bad things, the total area of life is clearly not all it is to suicide. Another important thing to keep in mind is that we, perhaps, can not know what will happen in the future. If we do not know what will happen in the future, how can we ever, using the utilitarian lens, decide whether we should suicide or not. If you are the person living through the fourth scenario, then you might think when you are ten that all there is to life is suffering, my life is an absolute disaster, and I see no way out, and your suicide. Think of the people in the concentration camps during the holocaust, who have no information about how the war is going outside. As the war progressed, their life got progressively worse until absolute evil was unleashed. Viktor Frankl, who suggested that a positive attitude toward life increases your survivability in the concentration camps, is not everyone in the camps.[9] Furthermore, even if you are consistently positive, death can still come at any moment when the oppressors decide to do so. How can these people know that the dawn is coming and not lose their meaning of life and will to live? Thus, the critical downfalls of the utilitarian lens are the following two. First, it relies on the expectation of life, but the future is not determined, and even if determined, it is not known to the person when making the decision. Second, no criteria can fully satisfy the degree of seriousness demanded by the finality of suicide, so criteria that may help us weigh things in other circumstances do not work in suicide.

\section{SOCIOLOGICAL LENS}

\subsection{Social facts}

Sociology, for Durkheim, is the study of social facts, which is something external to the individual. He defined social facts as "any way of acting, whether fixed or not, capable of exerting over the individual an external constraint." "Even if individual psychology held no more secrets for us" [10], there are still social problems that can't be answered. One way to think of how Durkheim views Sociology is that if we, individuals, are people with their parts, then society is just another person, but with us as its parts. This person, the society, is not just a compilation of its parts, which demands us to study its parts to understand the whole, but has a whole new being that is valuable to study on its own. The study of our blood, bacteria, organs, or brain is fascinating, but human beings are not just a collection of our blood, bacteria, organs, brain and whatever is part of us. Borrowing an idea from emergence, something completely new comes out of these parts combined, and some things that are not in the parts, when they are separated, emerge when they interact with each other or the whole. Thus, society is not just person after person, but an organism with its own nature, which you can call social facts. The investigation of social facts, for Durkheim, is the major concern of sociology.

Taking the sociology lens to suicide, "If, instead of seeing in them only separate occurrences, unrelated and to be separately studied, the suicides committed in a given society during a given period of time are taken as a whole, it appears that this total is not simply a sum of independent units, a collective total, but is itself a new fact sui generis, with its own unity, individuality and consequently its own nature-a nature, furthermore, dominantly social." [11]

\subsection{Data}

Durkheim, in his study of suicide, relied heavily on data and the interpretation of it. To study social phenomena, you must first establish that there are such phenomena. Durkheim showed, through data, that from 1841 to 1860 , the death rate, death per 100 inhabitants, stayed the same, but the suicide rate, suicides per 100,000 inhabitants, rose significantly, 8.5 per 100,000 inhabitants to 11.2 per 100,000 inhabitants. Thus, more people are committing suicide and the social phenomena that Durkheim wants to study indeed exist.

Using the same tool kit, Durkheim accessed other variables and examined how they relate to suicide. These variables include mental alienation, insanity, alcohol, geography, age group, season, religion, education level, etc. Amongst these, I will take a few examples from the list to demonstrate how sociology looks at suicide.

\subsubsection{Egoistic suicide and religion}

In his book, Suicide, Durkheim spent about 70 pages covering egoistic suicide, which is more than twice of other forms of suicide, including altruistic suicide, anomic suicide, and fatalistic suicide. In his analysis, religion is the prime example.

There are multiple variates when Durkheim analyses religion. First, he related education with religion to suicide. Data wise, more educated people are more likely to commit suicide, and protestants are more likely to commit suicide than Catholics. The three variates, education, religion and suicide, are tied together by Durkheim, and then he attempted to explain the pattern. Durkheim explains that protestants are less integrated as a community as opposed to Catholics. Education can be a factor because more education, to him, means the weakening of common prejudices. Since, at least from 
Durkheim's data, protestants tend to be more educated than Catholics, the analysis that less integration leads to more suicide is seemingly true.

\subsubsection{The Jewish exception}

The jews, however, is an exception to Durkheim's analysis of religion, education and suicide. The jews are the most educated group amongst them, Catholics and protestants, yet their suicide rate is the lowest. Durkheim explains that the jews, unlike the Christians, learn not to become a more critical person, which in turn weakens the common prejudices in us, but learn to be "better armed for the struggle".[11] Thus the jews are not less integrated as a result of education; Thus, their suicide rate is low.

More important than whether Durkheim's argument about Jews stands or falls is why he made such an argument. I will discuss more insights from the sociology lens as to how Durkheim argued for the Jewish exception later in the text.

\subsubsection{The men-women argument}

From the data of Durkheim, men suicide much more often than women, and Durkheim thought this is the result of the difference in education level. As he argued in his analysis of how religion, education and suicide relates, he argued that men suicide much more often than women because of their higher education level. As he theorised, more education means less social integration, which means egoistic suicide. However, in today's Europe and the whole world, males still commit suicide much more often than females. On the education end, women in Europe are not less educated than men, if not more than men. [12-14] The modern data on gender, education and suicide does not resemble what Durkheim had theorised.

\subsection{Assessment of the sociology lens}

Of course, Durkheim had a lot more exciting things to say about suicide and its relation to other variates, like how geography and historical events related to suicide, and other things like anomie, but the few analysis I presented in the previous text can already give us some insights to how sociologists like Durkheim view suicide.

From the men-women argument of Durkheim, we can see one of the results of the heavy reliance on data. Just like how deductive arguments rely solely on the validity of their assumptions, Durkheim's arguments relied heavily on the validity of his data. In his time, perhaps his data is accurate, but the phenomena he analysed no longer exists in our time, so his analysis fails to make sense.

From the Jewish exception, we can see a tendency in the scientific approach to questions. Once one develops a system of understanding, which we can call ideology, we tend to see everything through it, thus my usage of the word lens. When an anomaly occurs, the person tends to give patch fixes - arguments that explain exceptions that don't challenge the overall system - to their system rather than challenge the axioms of their system and change their ideology. This is perhaps because of the influence of reductive science, the dominant scientific approach of the west for perhaps 200 years, which has a heavy emphasis on a unified, systematic approach. From the reductionist point of view, I would even consider that giving a patch fix to an anomaly is generous since reductive science views anomalies as noise in the system that ought to be "conquered" with more precise experimental equipment.[15]

Thus, sociology is an expert in experiment design and data collection, at least much better than philosophers, but naive in their analysis. It merely gives logical possibilities and hypothetical theories, and Durkheim is well aware of this in his analysis of fatalistic suicide.[11]

\section{THE EXISTENTIAL LENS}

\subsection{The Existential movement and Camus}

There exists no such thing as existentialism - a unified system of ideas - but the existential movement, which includes works concerning human existence. The movement can trace its origin back to Descartes' "Cogito, ergo sum" [16]. People like Camus have a similar notion, but they appeal to intuition rather than reason. Usually, the word intuition is almost sacrilegious to philosophy, a taboo that must be avoided. Camus, however, argued, or more accurately I should say stated, that "We get into the habit of living before acquiring the habit of thinking." The existential project is more similar to metaphilosophy than the narrow sense of philosophy, at least under the context of the Anglo-American tradition.[17] Thus, existentialists start from our existence, a solid foundation, and then contemplate the world.

\subsection{Clarification}

Although Camus personally rejected the label "Existentialist" [18], Camus sees suicide as the "one truly serious philosophical problem". "All the rest- whether or not the world has three dimensions, whether the mind has nine or twelve categories - comes afterwards." Thus, it is not only not inappropriate to classify Camus as one that uses the existential lens, but also makes his ideas interesting ones to consider in the topic of suicide.

Another thing to clarify is that people like Camus and Kierkegaard rejected systematising philosophy. [19,20] It is the reason why their writing style is so distinct from others. Kierkegaard played multiple characters in his book [21]; Camus created numerous characters in his novels. Both of these writers rejected putting their ideas into a format because of how they view the world. Lay a template of system and order on this world, and that template will fray, shatter and break. If the world is 
fundamentally chaotic, then there is no need to force upon it an order. Therefore, the following passage will be in a different form. I will quote plenty because I think the original words have a certain magic. It is "private, unknowable, not to be articulated, having, literally, to do with something else; it transforms and lays waste and gives life, and kills." [22]

\subsection{The capacity of the person}

The first thing to establish before any thought is developed is the thinker himself, whether he can think about the question without being misguided, or in other words, whether he can have the capacity to think about suicide. I will briefly skim over these ideas like Camus did since he didn't take the challenge to the capacity to think as an important one. Camus didn't give a requirement list that offers what is specifically required, but he is objecting to some popular criteria for the capacity to think about suicide. Camus believes that a person can have the capacity to think about suicide, but his idea about capacity is rather different than how a rationable person would imagine. There is no need for complex logical manoeuvres to Camus because he thinks that "It is always easy to be logical; it is always impossible to be logical to the bitter end." [23] None can be rational to the bitter end, and death is that bitter end. In addition, Camus thinks there is no point to be rational when thinking about suicide, since to him, rationality imagines the whole subject as a sort of mind game rather than a judgment that demands action. Objectivity shouldn't be a requirement either because "there are truths but no truth" [23]. Each is their own master, and each has their own truth, so there is no point to impose objectivity upon the hopelessly subjective humans.

\subsection{The Absurd}

The Absurd is the starting point of Camus's ideas, so we shall explore the concept first. There is something absurd between humans' search for meaning and unity and the chaos and indifference of the world. This fundamental mismatch, or, for the lack of a better word, conflict, is the Absurd, which originates neither from us nor from the world but through the mismatched interaction. Another point that must be mentioned is that Camus thought that we don't reason our way to the Absurd. Instead, we awaken to it, and this notion is put forth most eloquently and elegantly by the words of Camus himself. The lengthy but worthy quote explains the origin of the Absurd better than all the words I can muster, so I present to you the following words.

"But if that reply is sincere, if it symbolises that odd state of soul in which the void becomes eloquent, in which the chain of daily gestures is broken, in which the heart vainly seeks the link that will connect it again, then it is as it were the first sign of absurdity. It happens that the stage sets collapse. Rising, street-car, four hours in the office or the factory, meal, street-car, four hours of work, meal, sleep, and Monday Tuesday Wednesday Thursday Friday and Saturday according to the same rhythm - this path is easily followed most of the time. But one day the "why" arises and everything begins in that weariness tinged with amazement. "Begins"- this is important. Weariness comes at the end of the acts of a mechanical life, but at the same time it inaugurates the impulse of consciousness. It awakens consciousness and provokes what follows. What follows is the gradual return into the chain or it is the definitive awakening." [23]

\subsection{Other Existentialists}

With the absurd established, Camus further distinguished himself from other existentialists. $\mathrm{He}$ mentioned Husserl, Kierkegaard, Jasper, Shestov and Heidegger, which to him are all escapists. These philosophers, according to Camus, all accepted the notion of absurd as the starting point. There, perhaps, is a similar, though different in their detail, concept that these philosophers accept as a starting point. Maybe there is some connection between what Kierkegaard calls Angst, what Heidegger calls Thrownness and what Camus calls the Absurd. These philosophers somehow all found some meaning at the end of their analysis.

Kierkegaard is a typical example. The philosopher argued that between aesthetics, ethics and faith, one should choose faith, and not through any reason but a leap. Camus sees their position as indefensible ones because, to him, it is ridiculous to find meaning in the world if your assumption is there is none.

Some might argue that finding meaning, as a result, is not in conflict with the assumption that there is no meaning because the word "meaning" in the assumption is referring to an inherent meaning, perhaps natural in this world or god-given, which differs from the meaning that was found at the end of the analyses of the philosophers previously mentioned, which are artificial ones. But to me, Camus' label of escapist can still stand because the creation of these artificial meanings are no different than how people settle for modest goals in order to not disappoint themselves. In the modest goal case, people are settling for modest goals to avoid the challenges of life; In the meaning case, people are artificially creating meanings — which are "unfounded" in the world - to avoid the glaring truth that there is no meaning and people can never find any.

\subsection{Sisyphus -- the way to live}

"The gods had condemned Sisyphus to ceaselessly rolling a rock to the top of a mountain, whence the stone would fall back of its own weight. They had thought for some reason that there is no more dreadful punishment than futile and hopeless labor" [23] But even in this 
condition, Camus argued that we still should not escape from life. Instead, we should face up to it with ardour and valour, and let us be indomitable and stoic in the battle of life, which Camus calls rebellion. Sisyphus triumphs in the rolling of the rock, for that god condemned him to the rolling of the rock to suffer, but he rejoices instead. Don't let one's rebellion melt into melancholy, and fight with all one has. When all hope is lost, in the moments of consciousness when Sisyphus or us "becomes conscious of his wretched condition", the fire of passion shall burn the brightest as one who is rid of hope can fully devote his energy to the actual living of his life, not lamenting the past or hoping for the future. Therefore, even if the task of Sisyphus is utterly fruitless, just as how our life is absurd and utterly meaningless, "one must imagine Sisyphus happy", just as how we should not suicide.

\section{COMPARATIVE ANALYSIS OF THE LENS}

\subsection{Why do I think about suicide?}

"There is but one truly serious philosophical problem, and that is suicide".[23] It is often said that philosophy begins in curiosity, but on the existential question, the drive is different. Unlike "whether or not the world has three dimensions, whether the mind has nine categories" [23], the existential question is no game. We do not live the games we often think about on our armchairs. At best, they are light-hearted entertainment compared to the existential questions, ones that one plays when one wants a distraction. The existential question is no entertainment; it is real and dreadful. It is real, for one can doubt anything but one's existence. It is dreadful, for no dogma can exempt one from the question. The existential question arises not because one's life is boring but because one's heart is beating. The contraction of cardiovascular muscles is the drums of war, a calling that urges one forth to face the question, to live or die? What should I do with my life?

\subsection{Comparative analysis}

In my analysis of the utilitarian argument on suicide, I mentioned how the area of life is not all there is to suicide; many other things need to be considered. From those challenges, one quickly begins to question whether one can ever incorporate everything into the equation. There is, perhaps, something inherently strange in using the area method, or any systematic method that utilizes categories to weigh things, as a way to determine whether you should kill yourself or not. There is, perhaps, a mismatch of tools, like if you are using "philosophical" tools to analyse meta-philosophical problems. It may be that the question of suicide is not one of whether a number is bigger than another, but a question of yes or no.
The sociology of Durkheim's has some methodological problems, one of them is whether sociology can ever be studied as a science. Durkheim loves social facts and objectivity, but he also wanted to study the collective consciousness, which is subjective because it is concerned with consciousness, not facts. Now there are cases where this paradox can be avoided, such as when you study law. It is indeed part of the collective consciousness, for laws are public, and in some cases, indeed represent the common will. It is also objective since most of them are written down on paper somewhere; the words are objective to everyone who can read properly. But in the case of suicide, I don't think you can find anything like a law that will be helpful in our investigation. Sure, you can find laws forbidding suicide or regulating it, but if all the people that killed themselves, which are the people we are interested in, are rebelling against that law, then why would you study the law in order to understand those people? Sure, you can find data on how many people suicide, but how does that help in your understanding of suicide, the act itself, not how it correlates with other variates. Another challenge is that the collectivism in Durkheim's method can be unsuitable in the topic of suicide. Is suicide a dominantly social fact that justifies the usage of the sociological lens? I think that contrary to how Durkheim approached the problem of suicide, the individual consciousness of the suiciders should be at the centre of analysis. Even if social facts are acting upon the person at the moment of decision, we should still study how these social facts influence the person rather than study the social facts and call it a day.

Phenomenology, which heavily influenced the existential philosophers that came after, is a response to the impoverishment by the sciences to selfhood. In a few words, empiricism and the rise of science around the nineteenth century had improved our ability to understand the world, but rather little had been done about our consciousness. Under the paradigm of science, our inner world becomes a kind of pseudo-knowledge, totally unreliable to be the basis of knowledge, and so our focus has been on the outside world, such as the objects we perceive or the laws of gravity. Husserl and other philosophers who are considered "continental" wanted to bring back the focus to ourselves. Their beginning point is often our intuition, which is not as unreliable as some scientists would claim. A typical example is that perhaps we can observe some representation of our experience, such as the release of dopamine when we experience happiness, but the qualia of the experience are within the person herself, which is beyond the explanatory power of data. The qualia of our experience might not be the most scientific subject of study, but they are necessary if we wish to study a human being. Rich in its knowledge of the self, the existential lens has a "home court" advantage over the other lenses. After all, suicide is the killing of the 
person herself, and so the understanding of the person is of vital importance.

Thus I conclude that the existential lense is the most suitable for contemplating suicide. It treats the subject with the right attitude and employs the most relevant method. The title of this paper is "Contemplating Suicide", and I can't provide a definitive answer on what is the most righteous course. But I can answer the question about the other side of death, life, and more specifically, the meaning of life. (There is no inseparable link between suicide and the loss of meaning of life).

On the one hand, the man begs for meaning, immortal and absolute meaning. On the other hand, man is afraid that the meaning is not what he wants, even if it is what he seemingly wants, not what he truly wants. Interpretation is an active process guided by our intention. We see the things we want to see, and so even if truth lays naked to us, we still can't discover it, for our intentions blind us. Aren't we all afraid that the truth is not what we want? The answer, perhaps, will never be a satisfactory one for every one of us. Thus man, like a master procrastinator, shelves the question and gets on with living, or leaves the question to his hope about (for) the future when a miracle will happen, and some (certain) truth will reveal itself. But the unsettling hearts of us are still beating and demand us no less than an interrogation of the question of suicide. And so man puzzles over the question. Worse, a man puzzles over whether he can ever solve the problem. There is no god to guide man, no guarantee. For those who abandon the gods, we are the lost; for those who do not, they port themselves comfortably in their harbours. But some primordial instinct urged us that truth is more important than comfort and that we shall never surrender to faith. For the ones who have sailed the storm for so long, the yearning for a new world is equally strong. But we forgot that we didn't sail forth into the ocean for a new harbour; we sailed forth because we are not content with the harbour. We demand something more than the comfort and stability provided. The respective harbours might be different in content, but they are the same in essence. We will find the exact same reason for departure in the new just as the old. Then, why would we settle for a new harbour if we already despised the old one?

The worst dilemma is that I don't even know what question to ask. Usually, philosophers raise a question and then argue about it, but in the existential question, I know little about what to ask, or whether I should ask about anything at all, for what drives me to the question is not curiosity but angst. The conscious intellectual capability of myself is no help, for it is utilising a tool that is fundamentally incapable of handling the question it needs to handle. But some things can help, for they add more tools to our arsenal of expression. Art, and things like art, can help, not as an end itself, but as a tool of expression, for it is less precise but far richer in the content it can express. I want to end with a few pieces of advice on how to explore the existential question. One doesn't explore it by thinking; one explores it by living. And so, instead of studying in a classroom, lab or office, listen to music, ponder on a painting, write a poem, or sing and dance your passion. Go on a subway without knowing your destination, eat at a restaurant you didn't book, pick up a hobby that you never knew, meet a human you would have never met. Enrich your existence with life, for they are the things to rely on when answering the existential question rather than logic.

\section{CONCLUSION}

In conclusion, I failed. I failed to answer whether you should suicide or not. But I hope my essay can be viewed as a noble failure because, conscious of its almost inevitable failure, this essay still, through its turmoil, tries to provide some possible suggestions on how you can explore the existential question and perhaps answer it. At the very end, I wish to give an account of what I think the answer would be.

Any proper answer to the existential question will be a personal, passionate and holistic answer. But don't take the list I have given too seriously, for the question is one you have to answer without any criteria, and that mere words can't encapsulate what I mean. The answer shall be private to the one. It shall be gut-wrenching perhaps, but blissful at the same time. It shall capture the diversity, colourfulness, chaos and beauty of our world. Human beings will settle for no less than that answer. You must make a choice; for any moment you don't, you choose to exist in this world.

So go on, answer the question.

\section{REFERENCES}

[1] Binswanger, L. (1963). Being-in-the-world. Basic Books, New York.

[2] Dworkin, R. (2011). Life's dominion: an argument about abortion, euthanasia, and individual freedom. Vintage.

[3] Nozick, R., \& Williams, B. (2014). 23. Anarchy, State and Utopia (pp. 107-114). Princeton University Press, Princeton.

[4] Singer, P. (2003). Voluntary euthanasia: a utilitarian perspective. Bioethics, 17(5 - 6), 526-541. SinnottArmstrong, Walter, Edward N. Zalta (ed.), (2019) "Consequentialism", The Stanford Encyclopedia of Philosophy ,https://plato.stanford.edu/archives/sum2019/entries /consequentialismVärnik, P. (2012). Suicide in the world. International journal of environmental research and public health, 9(3), 760-771. 
[5] Mill, J. S. (2008). Utilitarianism and on liberty: Including Mill's' Essay on Bentham'and selections from the writings of Jeremy Bentham and John Austin. John Wiley \& Sons, Hoboken.

[6] Moore, G. E., \& Baldwin, T. (1993). Principia ethica. Cambridge University Press, Cambridge.

[7] Singer, P. (2011). Practical ethics. Cambridge university press, Cambridge. Singer, P. (1996). Rethinking life and death: The collapse of our traditional ethics. Macmillan, New York.

[8] Fedden, R. (1938). Suicide; a social and historical study.

[9] Frankl, V. E. (1985). Man's search for meaning. Simon and Schuster, New York. Hanh, T. N. (2016). The miracle of mindfulness: An introduction to the practice of meditation. Beacon Press, Boston.

[10] Durkheim, E. (2014). The rules of sociological method: and selected texts on sociology and its method. Simon and Schuster, New York.

[11] Durkheim, E. (2005). Suicide: A study in sociology. Routledge, Oxford

[12] Eurostat. (2017). Education. Eurostat. https://stat.gov.pl/kobiety-i-mezczyzni-weuropie/bloc-2a.html?lang=en

[13] Eurostat. (2021, March). Gender statistics. Eurostat. https://ec.europa.eu/eurostat/statisticsexplained/index.php?title=Gender_statistics

[14] Eurostat. (2021, June 4). Population by educational attainment level, sex and age (\%) - main indicators. Eurostat. https://ec.europa.eu/eurostat/databrowser/view/edat _lfse_03/default/table?lang=en

[15] Kuhn, T. (2021). The structure of scientific revolutions (pp. 176-177). Princeton University Press, Princeton

[16] René Descartes, (1984) Principles of Philosophy: Translated, with Explanatory Notes. Vol. 24. Springer Science \& Business Media, Heidelberg.

[17] Husserl, E. (1927). "Phenomenology," edmund husserl's article for the encyclopaedia britannica* (1927) (R. E. Palmer, Trans.). Markfoster.net. http://www.markfoster.net/struc/phenomenology_h usserl_britannica.pdf Reprinted from Journal of the British Society for Phenomenology 2 (1971 ): 77-90 ; in Husserl's Shorter Works, pp.21-35.

[18] Camus, A., \& Thody, P. (1970). Lyrical and critical essays. Vintage Books, New York Cosculluela, V. (1994). The ethics of suicide prevention. International Journal of Applied Philosophy, 9(1), $35-41$.
[19] Kierkegaard, S. (2013). The concept of anxiety (pp 1-6). Princeton University Press, Princeton

[20] Kierkegaard, S. (2013). The sickness unto death (pp. 235-478). Princeton University Press, Princeton

[21] Kierkegaard, S. (2013). Kierkegaard's Writings, XI, Volume 11: Stages on Life's Way. Princeton University Press, Princeton.

[22] Baldwin, J. (2013). Another country. Vintage.

[23] Camus, A. (2013). The myth of Sisyphus. Penguin UK, London 